\title{
Correction: Online Guide for Electronic Health Evaluation Approaches: Systematic Scoping Review and Concept Mapping Study
}

Tobias N Bonten ${ }^{1,2 *}$, MD, PhD; Anneloek Rauwerdink ${ }^{3^{*}}$, MD; Jeremy C Wyatt ${ }^{4}$, MD, PhD; Marise J Kasteleyn ${ }^{1,2}$, $\mathrm{PhD}$; Leonard Witkamp ${ }^{5,6}, \mathrm{MD}, \mathrm{PhD}$; Heleen Riper ${ }^{7}, \mathrm{PhD}$; Lisette JEWC van Gemert-Pijnen ${ }^{8}$, PhD; Kathrin Cresswell ${ }^{9}$, $\mathrm{PhD}$; Aziz Sheikh ${ }^{9}, \mathrm{PhD}$; Marlies P Schijven ${ }^{3}, \mathrm{MD}, \mathrm{PhD}$; Niels H Chavannes ${ }^{1,2}$, MD, PhD; EHealth Evaluation Research Group ${ }^{10}$

${ }^{1}$ Department of Public Health and Primary Care, Leiden University Medical Centre, Leiden, Netherlands

${ }^{2}$ National eHealth Living Lab, Leiden, Netherlands

${ }^{3}$ Department of Surgery, Amsterdam Gastroenterology and Metabolism, Amsterdam UMC, Amsterdam, Netherlands

${ }^{4}$ Wessex Institute, University of Southampton, Southampton, United Kingdom

${ }^{5}$ Department of Medical Informatics, Amsterdam UMC, Amsterdam, Netherlands

${ }^{6}$ Ksyos Health Management Research, Amstelveen, Netherlands

${ }^{7}$ Department of Clinical, Neuro and Developmental Psychology, Vrije Universiteit, Amsterdam, Netherlands

${ }^{8}$ Department of Psychology, Health and Technology, Centre for eHealth and Wellbeing Research, University of Twente, Enschede, Netherlands

${ }^{9}$ Centre of Medical Informatics, Usher Institute, The University of Edinburgh, Medical School, Edinburgh, United Kingdom

${ }^{10}$ Please see acknowledgements section for list of collaborators

* these authors contributed equally

\section{Corresponding Author:}

Tobias N Bonten, MD, PhD

Department of Public Health and Primary Care

Leiden University Medical Centre

Department of Public Health \& Primary Care, Room V6-22

PO Box 9600

Leiden, $2300 \mathrm{RC}$

Netherlands

Phone: 31715268433

Email: t.n.bonten@lumc.nl

\section{Related Article:}

Correction of: https://www.jmir.org/2020/8/e17774

(J Med Internet Res 2020;22(8):e23642) doi: 10.2196/23642

In "Online Guide for Electronic Health Evaluation Approaches: Systematic Scoping Review and Concept Mapping Study ("J Med Internet Res 2020;22(8):e17774") the authors noted one error.

The metadata erroneously listed the group author "EHealth Evaluation Research Group" as having contributed equally. This has been corrected, and the group author is no longer listed as having contributed equally.
The correction will appear in the online version of the paper on the JMIR Publications website on August 21, 2020, together with the publication of this correction notice. Because this was made after submission to PubMed, PubMed Central, and other full-text repositories, the corrected article has also been resubmitted to those repositories 
This is a non-peer-reviewed article. Submitted 18.08.20; accepted 18.08.20; published 21.08.20.

Please cite as:

Bonten TN, Rauwerdink A, Wyatt JC, Kasteleyn MJ, Witkamp L, Riper H, van Gemert-Pijnen LJEWC, Cresswell K, Sheikh A, Schijven MP, Chavannes NH, EHealth Evaluation Research Group

Correction: Online Guide for Electronic Health Evaluation Approaches: Systematic Scoping Review and Concept Mapping Study

$J$ Med Internet Res 2020;22(8):e23642

URL: http://www.jmir.org/2020/8/e23642/

doi: $10.2196 / 23642$

PMID: $\underline{32822315}$

(CTobias N Bonten, Anneloek Rauwerdink, Jeremy C Wyatt, Marise J Kasteleyn, Leonard Witkamp, Heleen Riper, Lisette JEWC van Gemert-Pijnen, Kathrin Cresswell, Aziz Sheikh, Marlies P Schijven, Niels H Chavannes, EHealth Evaluation Research Group. Originally published in the Journal of Medical Internet Research (http://www.jmir.org), 21.08.2020. This is an open-access article distributed under the terms of the Creative Commons Attribution License (https://creativecommons.org/licenses/by/4.0/), which permits unrestricted use, distribution, and reproduction in any medium, provided the original work, first published in the Journal of Medical Internet Research, is properly cited. The complete bibliographic information, a link to the original publication on http://www.jmir.org/, as well as this copyright and license information must be included. 